\title{
Research on diversified application of modular high temperature ceramic kiln
}

\author{
Shanxin Feng ${ }^{1,2}$, Yurong Wang ${ }^{3}$ and Sone Simatrang ${ }^{1 *}$ \\ ${ }^{1}$ Faculty of Decorative Arts, Silpakorn University, Bangkok, 10700, Thailand \\ ${ }^{2}$ Engineering training centre, Qilu University of Technology, 250300, Jinan Shandong, China \\ ${ }^{3}$ Institute of Art and Design, Qilu University of Technology, Jinan, Shandong, China
}

\begin{abstract}
Modular ceramic kiln can meet more than 10 kinds of ceramic firing technology, such as carburizing, wood burning, soda burning,Shinoya, oxidation firing, reduction firing, which adopt a full range of safety warning device, monitor and record the whole process of fire, guarantee the stability of the firing process, and provide reference data for the next fire. Modular ceramic kiln can meet various of ceramic kiln firing technology after physical kiln experiments, and has many advantages such as less investment, quick effect, broad use, etc. which can be widely used in the laboratory of colleges, universities and scientific research process.
\end{abstract}

\section{Introduction}

Kiln is the most important firing equipment in ceramic production, China's ceramic industry has been born in the formation of ancient times like" three points to do, seven points to burn ceramic fire"in the proverb.[1] From the perspective of the development of the ceramic industry, the development of ceramic kiln plays a vital role. At present, the research on ceramic kiln on the market mainly focuses on how to better optimize the firing process, making the firing more energy-efficient and environmentally friendly.[2]However, often a kiln is only for the firing of a type of ceramic, and other firing can only design a kiln to meet the firing process. Although this approach achieves the goal of energy conservation and emission reduction, it also greatly increases the cost of ceramic firing and wastes effective resources.[3]

At present, the development of modular kiln is still in the primary stage in China. The reason is that the process of each firing cannot be well controlled and the safety of ceramic firing cannot be taken into account while meeting most firing processes. In this study, the advanced JT10701 temperature controller is used to select the temperature control curve with one key and precisely control each firing process.

Modular ceramic kiln, which not only has simple equipment, easy operation and safety, the scale can be based on the different situation, no pollution, and has the advantages of less investment, quick effect, wide use, which can be widely used in universities, laboratories and scientific research process.

\section{Modular ceramic kiln design}

The traditional model of ceramic kiln, exists inadequate fuel combustion, unreasonable spatial distribution, low factor of safety defects and the insufficiency, in the design.Through the method of simulation modeling, from the perspective of the overall control of the whole kiln design process using Rhino (Rhino) software to redesign of ceramic kiln, from the perspective of the three-dimensional simulation analysis was carried out on the kiln usage scenario, determine the add and reduce of module, to constantly optimize the internal space of the kiln using computer simulation technology.

Fluid heat transfer in the process of ceramic kiln. The nozzle Angle and other factors that affect the flow in the kiln can optimize and adjust the firing process of ceramics in the kiln, so as to enhance the control precision and make the whole process more effective.[5] Through the simulation analysis of ceramic kiln, from the simulated security analysis, appeared before the finished product of ceramic kiln (the use of ABAQUS software for stress analysis) in the process of ceramic kiln design, through the kiln model, analysis and computer simulation technology of the stress characteristics analysis.

\section{Establishment of modular ceramic kiln model}

Through the design of modular kiln, the basic parameters are established as external dimensions: $1000 \mathrm{~mm}$ long, $1000 \mathrm{~mm}$ wide, $1100 \mathrm{~mm}$ high .Internal dimensions $400 \mathrm{~mm}$ wide, $400 \mathrm{~mm}$ long and $500 \mathrm{~mm}$ high. Internal materials;Firebrick refractory cotton, power :9KW $380 \mathrm{v}$. Control mode: 4-20mapid analog signal,controller (three-phase power regulator) temperature curve in section 32; Heating element: u-shaped silicon carbon rod,

\footnotetext{
*Corresponding author’s e-mail: musenliu@foxmail.com
} 
maximum temperature $1350{ }^{\circ} \mathrm{C}$ insulation material: mullite fiber can burn wood;Can burn liquefied petroleum gas, used to adjust reducing atmosphere; Thermocouple platinum (single platinum rhodium)S indexing;Maximum allowable load of silicon carbon rod for electrode guard:less than $10 \mathrm{w} /$ square $\mathrm{cm}$ silicon carbide shed plate $300 \times 300 \times 8$ quantity 10 pieces;Shed board stent brick 80 number 30 pieces of high alumina porcelain tube diameter (d) 40, 28018 Chinese side door control interface, 32 programmable thermostat JT10701 type, with temperature control curve is a key control interface display selected working current, working voltage $220 \mathrm{v}$ is set.The bottom of the kiln is provided with a glaze spraying device port, and the top is provided with a wire protection embedded position. The three-dimensional view of the modular ceramic kiln thus constructed is shown in Figure 1.

According to the above parameters design modularization of ceramic kiln the graphic is shown in figure 2 , the kiln top view as shown in figure 3 , the front view as shown in figure 4.
Modular ceramic kiln bottom is equipped with electric stove wire protection device, when the temperature of $500 \sim 800$, by electric kiln, more than 800 USES or other gas kiln fire, open the electric stove wire protection device to protect kiln tungsten filament. It can save fuel, protect the environment.The ceramic view at the bottom of the crater is located in the ceramic kiln of $45 \mathrm{~cm}$ position, not only ensure the fire process, can also be on the inside of the kiln firing condition real-time monitoring at the same time.

Using glaze spraying device at the bottom of the kiln, jet nozzle with boron carbide (a kind of ceramic composite materials, has high temperature resistant corrosion resistant). The ceramic composite glaze injection device is located at the bottom of the modular ceramic kiln, which can be easily removed.During the firing process, the glaze can be projected to the interior of the kiln, which can be uniformly attached to the ceramic surface to achieve the ideal firing effect.

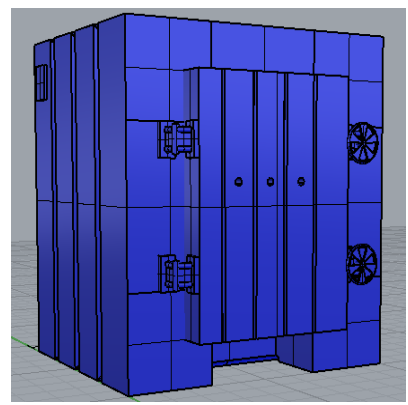

Figure 1. Three-dimensional diagram of ceramic kiln

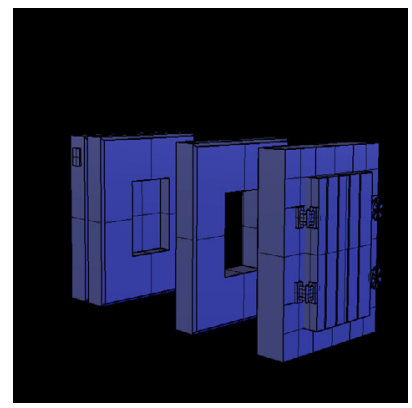

Figure 2. Modular ceramic explosion diagram

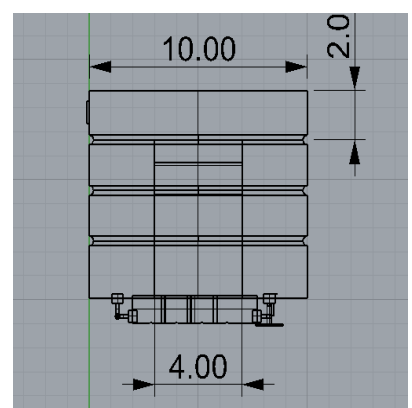

Figure 3. Modular ceramic kiln top view(unit/dm) 


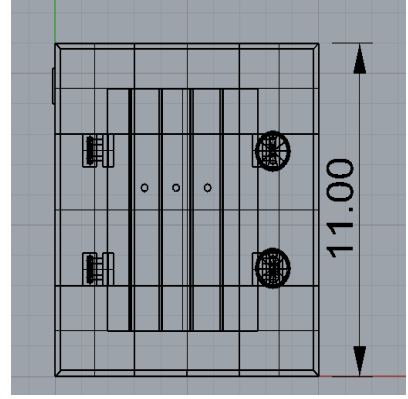

Figure 4. Front view of modular ceramic kiln(unit/dm)

\section{Feasibility analysis of modular kiln design}

By using three-dimensional modeling software, three-dimensional space modeling of ceramic kiln is carried out, and the overall composition of kiln is designed at the initial stage of kiln design. The most important problem of modular kiln is safety.

Because of the independent modular structure, the safety of ceramic kiln is a major test in the high temperature environment of ceramic firing. To this end, we use advanced kiln pressure safety system, using computer programming to control the ceramic firing in a reasonable safe range, once the pressure safety, will be through the pressure relief valve, pressure relief, temperature reduction treatment.Ensure the safety of ceramic kiln in firing process.

The sealing structure between modules, through special silicon carbide canopy sealing strip, the ceramic kiln is sealed by taking advantage of the different air pressure and temperature between inside and outside of the kiln, to ensure the normal firing of the modular ceramic kiln.In the process of firing, the injection device at the bottom of the kiln USES boron carbide composite material at the top, which can work in the high-temperature environment of the kiln and ensure the smooth progress of ceramic firing experiment.

The combustion reaction in the ceramic kiln is a reaction process between gases.It is assumed that the gas involved in the reaction is an ideal gas. $\mathrm{PV}=\mathrm{nRT}$ can be obtained from the ideal gas state equation. Under constant temperature, the relationship between partial pressure of gas and molar concentration can be written:

$\mathrm{P}_{\mathrm{A}}=\frac{n_{A}}{V} \mathrm{RT}=\mathrm{C}_{\mathrm{A}} \mathrm{RT}(1)$

The relationship between partial pressure and total pressure is:

$$
\mathrm{X}_{\mathrm{A}}=\frac{P_{A}}{P}(2)
$$

Using ABAQUS software to simulate the modular ceramic kiln force analysis, it is concluded that the design of ceramic kiln in response to satisfy the firewood carburizing fire craft process of soda burn process chi wild fire oxidation firing reduction burn and so on more than 10 kinds of ceramic firing process of burn limit value, can work normally in modular ceramic kiln have a physical test, the furnace pressure safety system to air pressure in the ceramic kiln to work near the limit value, the pressure within the ceramic kiln has remained at a normal level.

\section{$5 \quad$ Results and discussion}

The modular ceramic kiln can cope with more than 10 kinds of ceramic firing processes, such as carburizing and firing process, wood burning process, soda burning process, Zhiye firing, oxidation firing, and reduction firing. Moreover, the size of the ceramic kiln can be adjusted according to the amount of kiln firing, and can be fired according to different needs.

The use of a comprehensive safety warning device can solve 38 common problems and common hidden dangers in ceramic firing, monitor and record the whole process of firing, ensure the stability of each firing process, and provide reference data for the next firing. In the process of firing, the safety level in the firing process can be improved while the firing process is satisfied, the normal firing of the kiln is ensured, and the ceramic kiln is protected, thereby greatly improving the ceramic kiln using year.

The modular ceramic kiln is fired by electric furnace wire at low temperature, and the high temperature is fired according to the specific firing process, which can greatly save effective resources. The unique internal atomization spray design of the kiln can be uniformly atomized and sprayed into the kiln during the kiln firing process to meet the different firing process experiments. In the process of firing at the bottom of the kiln, since the top material is made of a composite material of boron carbide, it can work in the high temperature environment of the kiln to ensure the smooth progress of the ceramic firing experiment.

In the process of firing, the modular ceramic kiln can fully utilize and protect the inside of the different firing processes.

In the process of low-temperature firing, the green body is fired by electric furnace wire, and after reaching the temperature, the electric furnace wire is closed and protected according to different firing processes, the 
utilization rate of the ceramic kiln is improved, and improved the rate of firing.

Network remote intelligent control, the modular ceramic kiln can be networked, the process of different kiln firing is recorded and organized into a database, data reference for different usage scenarios, remote video visible function can be the whole process of firing Remote monitoring records capture the key points in the firing process.

The modular ceramic kiln ensures the safety of the firing process while ensuring the safety of the kiln firing. At the same time, it satisfies most of the firing, and can be selected according to different needs, and develop the future ceramic kiln.

\section{Conclusion}

(1) Modular ceramic kiln can cope with more than 10 kinds of ceramic firing processes, such as carburizing and firing process, wood burning process, soda burning process, Zhiye firing, oxidation firing, reduction firing, etc.

(2) Modular ceramic kiln can meet the firing process and both improve the safety level in the firing process.

(3) Modular ceramic kiln can make full use of and protect the internal furnace wire in the firing process according to different firing processes.

(4) The modular ceramic kiln can spray atomization uniformly into the furnace during firing, so as to satisfy the experiment of different firing process.

\section{Acknowledgements}

Special thanks for: Shandong Provincial People's Government Degree Committee, Shandong Province Graduate Education Quality Improvement Program "Modern Ceramic Art Creation", A Study on the Training Mode of International Art Design Talents under the Vision of "One Belt, One Road" in the Key Project of Teaching Reform Research Project of Undergraduate Universities in Shandong Province in 2018(Z2018S010).

\section{References}

1. Sun Huayun, Li Mingjing, \& Lu Yong. (2017). Analysis of 3D modeling prospect of industrial kiln based on bim technology. Shandong Metallurgy, v.39 No. 206 (06), 38-41.

2. Wu Zhihua, Yang Hui, Qin Fan, Ye Hai, \&Fang Liangjun. (2017) Application of electric kiln in Longquan celadon manufacture. Power demand side management (5).

3. Wu Hao. (2016) Research on the technology and materials of modern firewood burning art. New Art (4), 19-25.

4. Li Bingxin. (2015). The practice of soda-glaze in ceramic firing. (Doctoral dissertation).
5. Zhang Xingli. (2012). Study on the process of pottery making in Xuecheng site. (Doctoral dissertation).

6. Yali. (2009) Research on data warehouse for ceramic kiln design decision support system. (Doctoral dissertation, Wuhan University of Technology).

7. Yan Hanjun. (2006) Summary of energy saving technology for ceramic kilns in Europe. Ceramic Science and Art, 40 (1), 33-36. 